\title{
Double frameshift mutations in APC and MSH2 in the same individual
}

\author{
Claudio Soravia • Celia D. Delozier • Zuzana Dobbie • \\ Claudine Rey Berthod • Eviano Arrigoni • \\ Marie-Anne Bründler • Jean-Louis Blouin • \\ William D. Foulkes • Pierre Hutter
}

Published online: 17 November 2006

(C) Springer-Verlag 2006

The online version of the original article can be found at http://dx.doi. org/10.1007/s00384-005-0764-z.

C. Soravia

Clinic of Visceral Surgery,

Geneva University Hospital,

Geneva, Switzerland

C. D. Delozier · J.-L. Blouin

Division of Medical Genetics,

Geneva University Hospital,

Geneva, Switzerland

Z. Dobbie

Division of Medical Genetics,

Department of Clinical and Biological Sciences,

Basel, Switzerland

C. R. Berthod $\cdot$ P. Hutter

Genetics Unit, ICHV,

Sion, Switzerland

E. Arrigoni

Gastroenterology Practice,

Geneva, Switzerland

M.-A. Bründler

Division of Clinical Pathology,

Geneva University Hospital,

Geneva, Switzerland

W. D. Foulkes

Departments of Medicine,

Oncology and Human Genetics,

McGill University,

Montreal, Québec, Canada

C. Soravia $(\bowtie)$

Route de Chêne 11,

1207 Geneva, Switzerland

e-mail: csoravia@hin.ch
Owing to an unfortunate oversight, the article Double frameshift mutations in APC and MSH2 in the same individual by Soravia et al. has been published twice:

Volume 20, Issue 5, on pages 466-470

Volume 21, Issue 1, on pages $79-83$

The article with DOI 10.1007/s00384-005-0772-z has been eliminated. Readers will be automatically redirected to the article with DOI 10.1007/s00384-005-0764-z. 